\title{
Pediatric Spontaneous Discitis: A Case Report
}

\author{
Erkan Çakmak ${ }^{1}$ Hamza Karabağ $^{1}$ A. Celal İplikçioçlu ${ }^{1}$ \\ ${ }^{1}$ Department of Neurosurgery, Faculty of Medicine, Harran \\ University, Sanliurfa, Turkey \\ Address for correspondence Erkan Çakmak, MD, Department of \\ Neurosurgery, Faculty of Medicine, Harran University, Sanliurfa, \\ Turkey (e-mail: erkcakmak1974@hotmail.com).
} Indian J Neurosurg 2015;4:46-48.

\begin{abstract}
Keywords

- dislocation

- children

- inflammation

- disc

Discitis in children is a benign self-limiting inflammatory or infectious lesion of the intervertebral disc space. Spondylitis/spondylodiscitis is still an uncommon diagnosis, often with delay in diagnosis and treatment due to uncharacteristic symptoms. The aim of this study is to increase the awareness and outline a pattern of investigation and treatment. The clinical signs were general irritability, abdominal or hip pain, and refusal to walk or to sit. The unspecificity of the symptoms, laboratory findings, and the late plain radiology detection does often delay the final diagnosis.
\end{abstract}

\section{Introduction}

The purpose of this case is to increase the awareness of the uncommon diagnosis of spondylitis/spondylodiscitis and to outline a pattern of investigation and treatment. The uncharacteristic symptoms, especially in children, often result in delayed diagnosis and treatment. The incidence of spondylodiscitis is approximately $1: 250,000 .^{1}$ Compared to the number of all infectious bone diseases, spondylitis/ spondylodiscitis makes up for only 2 to $4 \%{ }^{1}$ In spondylitis, the inoculation usually occurs by hematogenous spread to the vertebral body. If the infection spreads to the intervertebral space, it is called spondylodiscitis. In children, there is a possibility of isolated infection of the intervertebral space (discitis) due to the presence of vascular channels in the cartilaginous region of the discs. ${ }^{2}$ Bacterial infection can produce secondary reactive inflammatory changes of a disc space or infection of the space itself. ${ }^{2,3}$ Staphylococcus aureus appears to be the most common organism. ${ }^{4}$ Also, there are reports about gram-negative, lowvirulent, and atypical organisms that are frequently isolated. ${ }^{5,6}$ Diagnosis is difficult and is often delayed as children complain of vague symptoms of back, hip, or abdominal pain. General irritability and a refusal to walk or to stand are the main clinical signs; the laboratory tests are nonspecific. $^{7}$

\section{Case Study}

This case involved a 2-year-old child. Clinical manifestations included general irritability, abdominal pain, reluctance to sit or to walk, local tenderness, and refusal to flex the spine. Symptoms had been present from the past 10 days. The white blood cell count $\left(16,200 \mathrm{~mm}^{3} / \mathrm{dL}\right)$ as well as the erythrocyte sedimentation rate was elevated in patient $(30 \mathrm{~mm} / \mathrm{hr}$ ). A blood culture was performed and was found negative. Magnetic resonance imaging (MRI) study of T1-weighted images showed a decreased signal in the vertebral bodies involved, indicating that the medullary elements of these vertebrae were involved in the inflammatory process. T2-weighted imaging showed herniation of a portion of the disc, or the accumulation of fluid from the inflammation of the disc space, into the spinal

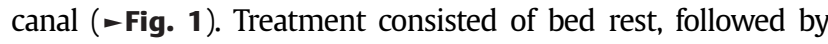
immobilization of the patient receiving oral antibiotics for 3 weeks. Although our patient recovered completely by the 2nd week, the symptoms improved dramatically in 48 to 72 hours, especially in this case after treatment with antibiotics. The patient did not develop scoliosis or kyphosis (-Fig. 2).

\section{Discussion}

Although the causes of nonspecific discitis in children remain controversial, bacterial infection is undoubtedly published online March 20, 2015
DOI http://dx.doi.org/ $10.1055 / \mathrm{s}-0035-1549129$. ISSN 2277-954X. (c) 2015 Neurological Surgeons' Society of India
License terms

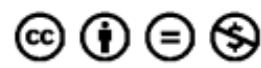




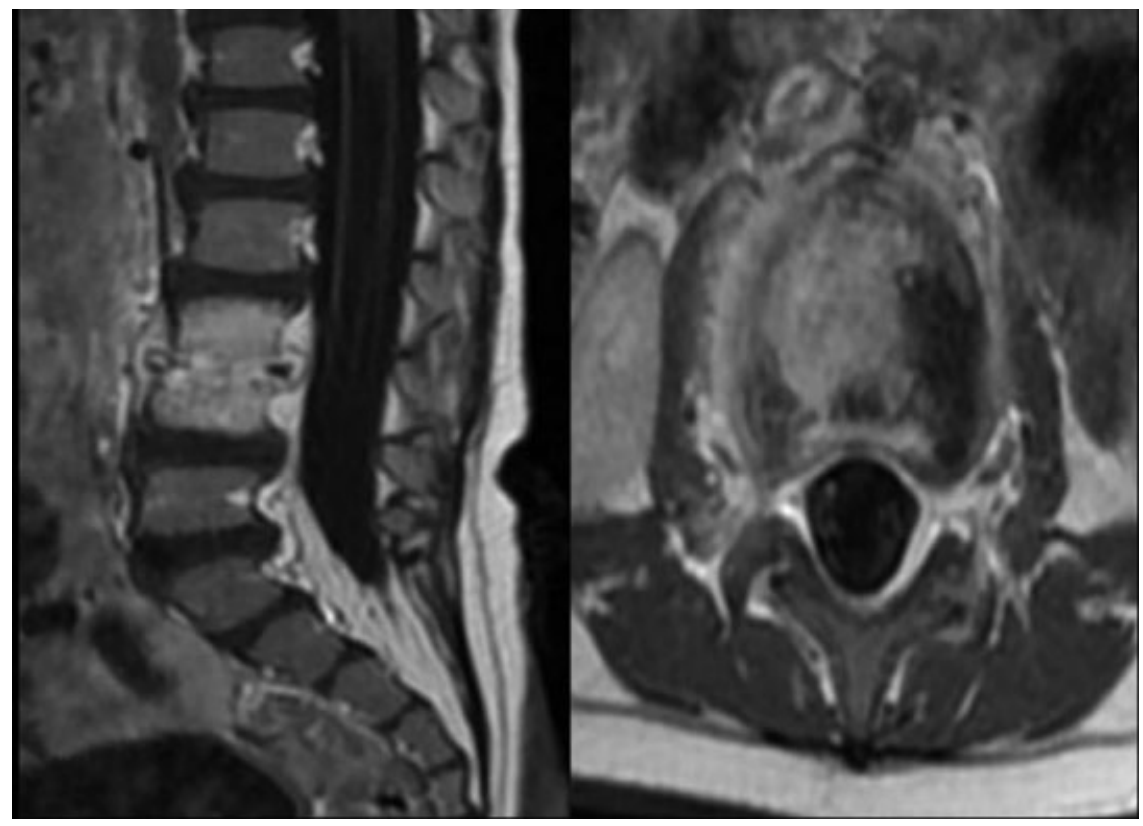

Fig. 1 T1-weighted magnetic resonance postcontrast image of a patient with discitis of L3/L4. There is narrowing of the disc space and retrograde protrusion of a portion of the disc or fluid from inflammation. The third and fourth lumbar vertebral bodies showed decreased signal intensity, which indicates that the medullary elements of these vertebrae are involved in the inflammatory process.

responsible for many. It is still an uncommon diagnosis and mimics neuromuscular disorders, Scheuermann disease, pyelonephritis, appendicitis, septic arthritis, osteomyelitis, and meningitis. ${ }^{8}$ Bacterial infection can produce secondary reactive inflammatory changes of a disc space or infection of the space itself., ${ }^{2,9}$ S. aureus appears to be the most common organism. ${ }^{4}$ Diagnosis is difficult and is often delayed as children complain of vague symptoms of back, hip, or abdominal pain. General irritability and a refusal to walk or to stand are the main clinical signs. Laboratory tests are nonspecific. ${ }^{7}$ MRI now reveals anatomical detail and may show specific localization of the disease to the disc space as well as help to rule out other processes. MRI is a noninvasive procedure, although its usefulness in young children can be hampered by the necessity for sedation., ${ }^{2,9}$

The cases reported that pediatric spondylitis/spondylodiscitis is still an uncommon diagnosis often with delayed diagnosis and treatment due to the uncharacteristic symptoms.

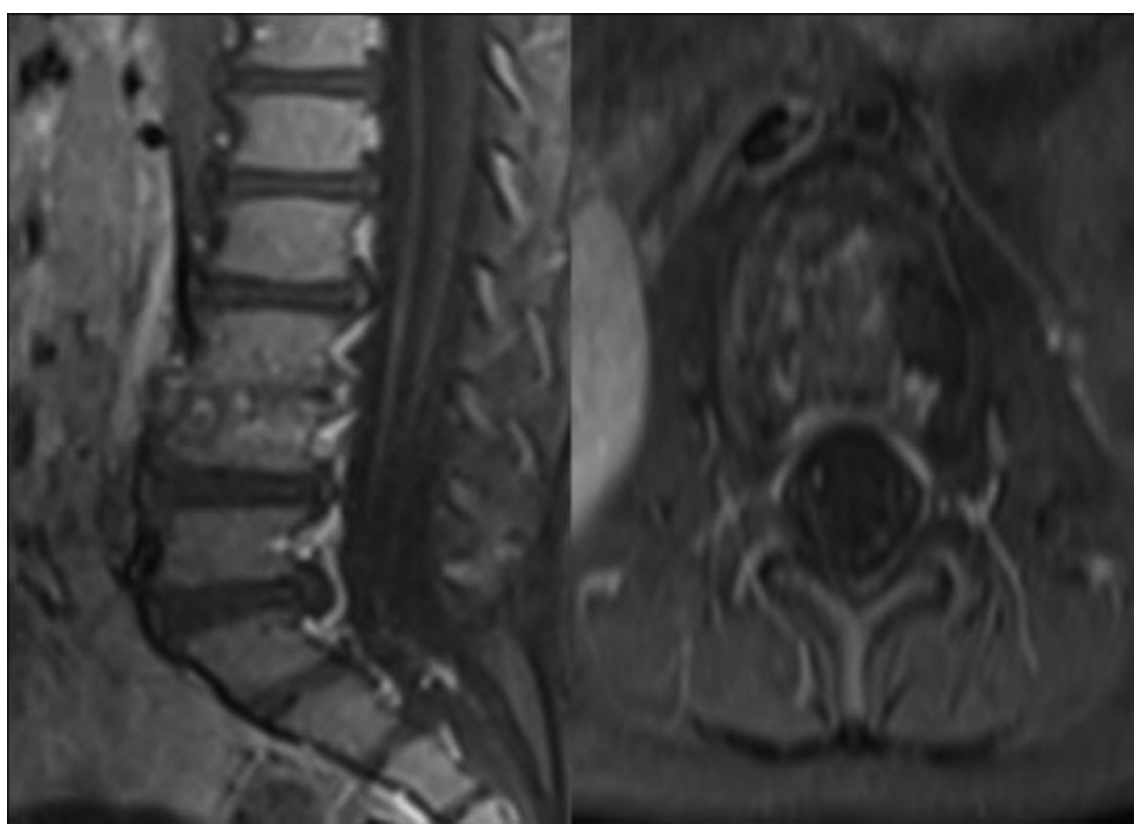

Fig. 2 Contrast enhanced T1-weighted MRI of patient after treatment with antibiotics. 
48 Pediatric Spontaneous Discitis: Case Report Çakmak et al.

\section{References}

1 Digby JM, Kersley JB. Pyogenic non-tuberculous spinal infection: an analysis of thirty cases. J Bone Joint Surg Br 1979;61(1): 47-55

2 Crawford AH, Kucharzyk DW, Ruda R, Smitherman HC Jr. Diskitis in children. Clin Orthop Relat Res 1991;(266):70-79

3 Ryöppy S, Jääskeläinen J, Rapola J, Alberty A. Nonspecific diskitis in children. A nonmicrobial disease? Clin Orthop Relat Res 1993; (297):95-99

4 Wenger DR, Bobechko WP, Gilday DL. The spectrum of intervertebral disc-space infection in children. J Bone Joint Surg Am 1978;60(1):100-108
5 Carragee EJ. Pyogenic vertebral osteomyelitis. J Bone Joint Surg Am 1997;79(6):874-880

6 Frederickson B, Yuan H, Olans R. Management and outcome of pyogenic vertebral osteomyelitis. Clin Orthop Relat Res 1978; (131):160-167

7 Scoles PV, Quinn TP. Intervertebral discitis in children and adolescents. Clin Orthop Relat Res 1982;(162):31-36

8 Maliner LI, Johnson DL. Intervertebral disc space inflammation in children. Childs Nerv Syst 1997;13(2):101-103, discussion 104

9 Gabriel KR, Crawford AH. Magnetic resonance imaging in a child who had clinical signs of discitis. Report of a case. J Bone Joint Surg Am 1988;70(6):938-941 